\title{
КОРРЕКЦИОННО-РАЗВИВАЮЩИЕ ВОЗМОЖНОСТИ ЭКОТЕРАПИИ В РАЗВИТИИ СВЯЗНОЙ УСТНОЙ РЕЧИ ДОШКОЛЬНИКОВ С ОБЩИМ НЕДОРАЗВИТИЕМ РЕЧИ'
}

\section{CORRECTIVE-DEVELOPING OPPORTUNITIES OF ECOTHERAPY IN THE DEVELOPMENT OF CONNECTED SPEAKING OF PRESCHOOLERS WITH GENERAL SPEECH UNDER DEVELOPMENT}

\section{N. Minaeva}

Summary: The article is devoted to the problem of improving correctional work on the development of speech in children with general speech underdevelopment (GDH) of preschool age. The authors considered the possibilities of using ecotherapy as a means of developing coherent oral speech in children of this category. The article analyzes the concept of "ecotherapy», considers its types and correctional and developmental opportunities in overcoming the developmental deficiencies of children with disabilities. The article presents the results of an experimental study aimed at determining the content of speech therapy work on the development of coherent speech of preschoolers with OHP in the course of classes using ecotherapy.

Keywords: ecotherapy, preschoolers with general speech underdevelopment, coherent oral speech, correctional work, speech therapy classes.
$\mathrm{B}$ последние годы отмечается значительное расширение спектра форм и областей применения нетрадиционных технологий, методов и средств в отечественной и зарубежной логопедической практике. Одним из таких средств является экотерапия, объединяющая положительное воздействие окружающей природы с современными технологиями логопедической, психологической и дефектологической поддержки.

Экотерапия как отдельное направление терапевтической деятельности, основанное на природных методах исцеления, появилась не так давно, в 60-х годах XX века. Термин «экотерапия» («зеленая терапия», «природная терапия», «терапия Земли» и др.), введенный Г. Клайнбеллом в 1996 году, обозначает различные методы физического и психологического целебного воздей-

\author{
Минаева Наталья Геннадьевна \\ К.n.н., дочент, ФГБОУ ВО «Мордовский государственный \\ педагогический университет имени М.Е. Евсевьева» \\ (2. Саранск) \\ natmi27@yandex.ru
}

Аннотация: Статья посвящена проблеме совершенствования коррекционной работы по развитию речи детей с общим недоразвитием речи (ОНР) дошкольного возраста. Авторами рассмотрены возможности применения экотерапии как средства развития связной устной речи детей рассматриваемой категории. В статье проанализировано понятие «экотерапия», рассмотрены ее виды и коррекционно-развивающие возможности в преодолении недостатков развития детей с ограниченными возможностями здоровья. Представлены результаты опытно-экспериментального исследования, направленного на определение содержания логопедической работы по развитию связной речи дошкольников с ОНР в процессе занятий с использованием экотерапии.

Ключевые слова: экотерапия, дошкольники с общим недоразвитием речи, связная устная речь, коррекционная работа, логопедические занятия.

ствия, основанные на контакте человека с природной средой [3].

Как отмечает С.Н. Николаева, в широком смысле экотерапией можно назвать реабилитационную методику, в которой используются средства природы. Такой подход позволяет рассматривать термин «экотерапия» как собирательное понятие для обозначения гарденотерапии, анималотерапии, флоротерапии, песочной терапии и т.д. [5, с. 17].

Другой подход, отраженный в работах О.Б. Гонтарь, В.К. Жирова, И.В. Калашниковой, Н.В. Салтан, определяет экотерапию как особую методику, посредством которой формируются отношения «я - природа», то есть природа выступает как участник терапевтического процесса. В

Исследование выполнено в рамках гранта на проведение научно-исследовательских работ по приоритетным направлениям научной деятельности вузов-партнеров по сетевому взаимодействию ФГБОУ ВО «Чувашский государственный педагогический университет им. И. Я. Яковлева» по теме «Научно-методические аспекты применения инновационных образовательных технологий в коррекционной работе с дошкольниками с ограниченными возможностями здоровья» 
таком случае речь идет о самостоятельной реабилитационной технике, требующей особого внимания, изучения и разработки. Данная техника была успешно апробирована данными учеными в качестве средства профилактики негативных эмоциональных состояний испытуемых и использована как средство их социально-психологической адаптации [2; 3].

В научно-практических работах более подробно раскрыты коррекционно-развивающие возможности таких экотрерапевтических техник, как гарденотерапия и анималотерапия.

Гарденотерапия - это вид экотерапии, направленный на физическую и социальную адаптацию людей с ОВ3 посредством активного и/или пассивного взаимодействия с растениями. По мнению О.Б. Гонтарь, Т.В. Казак, И.В. Калашникова, И.Н. Мазуренко, О.Ю. Носатенко, Е.А. Святковская, Н.Н. Тростенюк, Е.П. Шлапак, применение гарденотерапии в коррекционной работе с детьми с нарушениями речи позволяет: развивать основные моторные навыки, мышечную координацию, гибкость пальцев; укреплять иммунитет с помощью растений, выделяющих фитонциды (биологически активные вещества, убивающие патогенные микроорганизмы); совершенствовать работу всех сенсорных каналов [2, с. 10].

Зоотерапия или анималотерапия - это вид экотерапии, использующий животных и их образы для оказания психотерапевтической помощи людям с ограниченными возможностями. Как самостоятельный метод анималотерапия начал приобретать популярность со второй половины XX века, когда учеными было доказано, что наибольший эффект лечения с помощью животных достигается в результате прикосновений к ним, то есть тактильного контакта [1, с. 30].

А.В. Гаврилова, М.А. Большакова отмечают, что к наиболее разработанным направлениям активной анималотерапии относятся: иппотерапия (взаимодействие с лошадьми), канистерапия (собаколечение), фелинотерапия (кошколечение), дельфинотерапия, гирудотерапия (лечение пиявками) и др. Наряду с активными видами анималотерапии терапии существуют и пассивные - наблюдение за животными (за птицами, за пресмыкающимися, за рыбками и др.) [1, с. 31].

Согласно классификации, предложенной A. Kopytin и M. Rugh, анималотерапия имеет четыре направления:

1. HAl - humar-animal interaction - взаимодействие ребенка с дружелюбным и обученным животным в присутствии «вожатого», который направляет разговор, включает в него рассказ о животном, некоторые показательные трюковые элементы;
2. AAA - animal assisted activity - совместная с животным активность, физическая деятельность (чаще всего групповая). Это физические упражнения, игры, эстафеты, прогулки, которые выполняются в содружестве и тесном контакте с дружелюбным и обученным животным;

3. AAE - animal assisted aducation - обучение с использованием животного на индивидуальных занятиях с детьми или как элемента развивающих групповых занятий;

4. ААТ - animal assisted therapy - лечение с использованием собаки. Это непосредственная реабилитация (индивидуальная или подгрупповая) с использованием специально обученного животного, которая проводится курсом по заранее разработанным программам, а состояние детей оценивается в динамике [8, с. 69].

М.В. Политыкин указывает, что даже образы животных могут производить коррекционный эффект: фильмы о животном мире помогают расслабиться и улучшают настроение; мягкие игрушки (плюшевые мишки, собачки, лошадки и т.п.) являются незаменимым оборудованием при работе с детьми дошкольного возраста; наглядные пособия с изображениями животных привлекают внимание детей и повышают их активность на логопедических занятиях [6, с. 72].

К.Ю. Яковлева отмечает, что использование на логопедических занятиях не самих животных, а даже их образов, благотворно влияет на коррекционный процесс:

- игры с мягкими игрушками животных и птиц вызывают у дошкольников с нарушением речи положительные эмоции, помогают задействовать тактильные каналы, развивают восприятие и внимание;

- чтение и инсценирование сказок о животных развивает мышление и воображение детей, увеличивает творческий потенциал;

- просмотр фрагментов фильмов о животных расслабляет и привлекает внимание детей;

- анималотерапевтические игры («Зверинец», «Крокодил» и др.), телесно-ориенированные упражнения («Попугай», «Муха», «Сороконожка», «Петушиный бой» и др.) позволяют корригировать эмоционально-волевую сферу;

- скороговорки, чистоговорки, стихи, стихи-небылицы, загадки, потешки о животных позволяют дифференцировать и автоматизировать звуки, развивать речь детей, стимулировать общение [7].

В ходе опытно-экспериментального исследования нами было разработано и апробировано содержание коррекционно-логопедического воздействия, направленного на развитие связной устной речи детей дошкольного возраста с ОНР средствами экотерапии. В ис- 
следовании принимали участие 14 дошкольников (5-6 лет) с логопедическим заключением «Общее недоразвитие речи III уровня», обучающиеся в МДОУ «Детский сад № 65 комбинированного вида» г.о. Саранск.

Коррекционная работа с детьми дошкольного возраста с ОНР осуществлялась в три этапа.

I этап - подготовительный, включающий выявление противопоказаний у детей к проведению занятий с использованием средств экотерапии (аллергия, повреждения и заболевания кожи, фобии, направленные на животных или растения и др.); разработку содержания занятий по развитию связной устной речи средствами экотерапии, подбор необходимого наглядно-демонстративного материала.

II этап - экскурсионный, включающий организацию и проведение экскурсий в городской зоопарк.

III - основной, включающий проведение логопедических занятий по развитию связной устной речи средствами экотерапии (гарденотерапия и анималотерапия).

Экспериментальное обучение предполагало реализацию трех основных блоков работы:

I блок - Работа по развитию лексико-грамматического строя речи. Данный блок включал три направления.

1. Развитие лексической стороны речи: расширение объема словаря; уточнение значения слов; совершенствование процесса перевода слов из пассивного словаря в активный. В ходе реализации данного направления использовались следующие приемы:

- активизация словаря по определенной теме (беседа о растении или животном);

- отгадывание растений или животных по описанию;

- подбор синонимов и антонимов к определенным словам;

- подбор частных понятий к общему понятию и наоборот;

- объяснение смысла устойчивых выражений, пословиц и поговорок, содержащих упоминание о растении или животном.

2. Развитие грамматической стороны речи: совершенствование навыков словообразования; совершенствование навыков словоизменения. В ходе реализации данного направления использовались следующие приемы:

- образование уменьшительно-ласкательных существительных;

- дифференциация глаголов совершенного и несовершенного вида, невозвратных и возвратных глаголов, глаголов с наиболее продуктивными приставкам;

- образование притяжательных, качественных и относительных прилагательных;

- употребление предложно-падежных конструкций существительных;

- согласование существительных с прилагательными и глаголами.

3. Развитие синтаксической стороны речи: закрепление умений правильно строить предложения, согласовывать слова в предложении, использовать в речи простейшие виды сложносочиненных и сложноподчиненных предложений. В ходе реализации данного направления использовались следующие приемы:

- составление предложений по образцу и самостоятельно;

- составление сложных предложений путем добавления придаточных предложений;

- ответы на вопросы.

I/ блок - Работа по развитию диалогической связной устной речи. Данный блок включал два направления.

1. Развитие собственно речевых умений: закрепление умений вступать в общение, поддерживать и завершать общение, учитывать условия и ситуацию общения; говорить выразительно в нормальном темпе.

2. Развитие умения речевого этикета: совершенствовать навык речевого общения в ситуациях обращения, знакомства, приветствия, привлечения внимания, приглашения, просьбы, извинения, благодарности, прощания.

В ходе реализации данных направлений использовались следующие приемы:

- побуждение к построению вопросительного высказывания;

- репродукция вопросительной интонации и их собственная продукция;

- упражнение детей в приветствии и прощании со сверстниками и взрослыми;

- активизация в речи детей познавательных вопросов как средства исследования проблемной ситуации и получения информации.

III блок - Работа по развитию монологической связной устной речи. Данный блок включал три направления.

1. Развитие описательной связной устной речи. В ходе реализации данного направления использовались следующие приемы:

- описание растений и животных на основе их восприятия; 
- описание растений и животных из опыта;

- описание картин, содержащих изображения растений и животных (предметных, сюжетных и пейзажных).

2. Развитие повествовательной связной устной речи. В ходе реализации данного направления использовались следующие приемы:

- пересказ литературных произведений о животных и растениях;

- составление рассказа по сюжетной картине (серии картин) о животном;

- составление повествований из опыта;

- составление рассказов на основе воображения (придумывание продолжения и окончания рассказа о животных и растениях; придумывание рассказа по плану; придумывание рассказа на заданную тему).

3. Развитие связной устной речи-рассуждения. В ходе реализации данного направления использовались следующие приемы:

- упражнения в отыскивании причин и следствий собственных действий;

- выявление причинно-следственных отношений между объектами и явлениями (животные, растения, человек, погодные явления и т. п.), изображенными на картинке;

- объяснение пословиц, отгадывание загадок о растениях и животных.

Основной путь повышения эффективности оказанного коррекционно-логопедического воздействия заключался в использовании разнообразных форм и методов работы:

1. наблюдение, в процессе которого дети не только познавали внешние параметры объектов природы (окрас, строение, размер и др.), опираясь на различные способы восприятия (зрительное, слуховое, тактильное и др.), но и приобретали навыки практического преобразования природы (уход за растениями и животными, создание подделок и рисунков на основе наблюдений и др.);

2. элементарный эксперимент, дающий реальные представления о различных сторонах изучаемого объекта, его взаимоотношения с другими объектами и со средой обитания. В процессе проведения экспериментов (посев семян, применение основных агротехнических приемов по уходу за растениями и др.) происходило обогащение памяти детей, активизировались их мыслительные процессы, развивалась мелкая моторика;

3. занятия, включающие как стандартные методы, так и уникальные авторские приемы, основанные на применении экотерапии.

Для развития связной речи у детей дошкольного возраста с ОНР средствами гарденотерапии применялись нижеперечисленные задания:

- описание процесса работы по посадке и уходу за растением;

- рассказывание сказки для посаженного растения;

- работа с готовым текстом о растениях (исправление ошибок, дополнение пропусков, придумывание окончание рассказа и т. д.).

Для развития связной речи у детей дошкольного возраста с ОНР средствами анималотерапии применялись нижеперечисленные задания:

- составление рассказа о конкретном животном, увиденном на экскурсии;

- составление рассказа по сюжетной картине или серии сюжетных картин о животном;

- работа с готовым текстом о животном (исправление ошибок, дополнение пропусков, придумывание окончание рассказа и т.д.);

- пересказ прочитанного текста о животном.

Проведенная коррекционно-логопедическая работа с детьми дошкольного возраста с ОНР была нацелена на развития связной устной речи и включала три блока: работу по развитию лексико-грамматического строя речи; работу по развитию диалогической связной устной речи; работу по развитию монологической связной устной речи. В рамках каждого из выше указанных блоков применялись не только традиционные методы и приемы логопедического воздействия, но и средства экотерапии (гарденотерапия и анималотерапия). Апробация предложенного содержания коррекционно-логопедической работы показала его эффективность. Таким образом, экотерапия, основанная на активном и пассивном взаимодействии с окружающей природой, способна стать эффективным средством комплексного коррекционнологопедического воздействия на дошкольников с нарушениями речи и оказать положительное влияние на их речевое развитие.

\section{ЛИТЕРАТУРА}

1. Гаврилова, А.В. Зоотерапия / А.В. Гаврилова, М.А. Большакова. // Жизнь с ДЦП. Проблемы и решения. - 2014. - № 4. - С. 30-32.

2. Гонтарь, 0.Б. Программа дополнительного образования «Экотерапия для детей 6-7 лет с речевыми нарушениями»: методическое пособие / 0.Б. Гонтарь, Е.А. Святковская, Н.Н. Тростенюк, И.В. Калашникова, 0.Ю. Носатенко, Е.П. Шлапак, И.Н. Мазуренко, Т.В. Казак. - Апатиты: КаэМ, 2013. - 54 с. 
3. Калашникова, И.В. Экологическая терапия как коррекционно-педагогический элемент в комплексном подходе при лечении логоневроза у дошкольников / И.В. Калашникова, Н.В. Салтан, О.Б. Гонтарь, В.К. Жиров. // Образование и наука. - 2016. - № 8. - С. 127-144.

4. Катмакова, В.А. Гарденотерапия - путь к оздоровлению детей с ограниченными возможностями / В.А. Катмакова. // Социальная работа. - 2015. - № 8. - C. 32-36.

5. Николаева, С.Н. Система экологического воспитания дошкольников / С.Н. Николаева. - М. : Мозайка-Синтез, 2010. - 256 с.

6. Политыкин, М.В. К животным на поправку / М.В. Политыкин. // Будь здоров. - 2015. - № 3. - С. 69-73.

7. Яковлева, К.Ю. Технология «Анималотерапия» в логопедической работе / К.Ю. Яковлева. // pedportal.net: международный образовательный портал. URL: https://pedportal.net/sko19.ucoz.ru/index/tekhnologija-animaloterapija_quot_v_logopedicheskoj_rabote/0-36.htm (дата 0бращения : 24.09.2020).

8. Kopytin, A., and M. Rugh, 2016. Green Studio: nature and the arts in therapy. British Journal of Special Education, 4(9): 68-72.

() Минаева Наталья Геннадьевна (natmi27@yandex.ru).

Журнал «Современная наука: актуальные проблемы теории и практики»

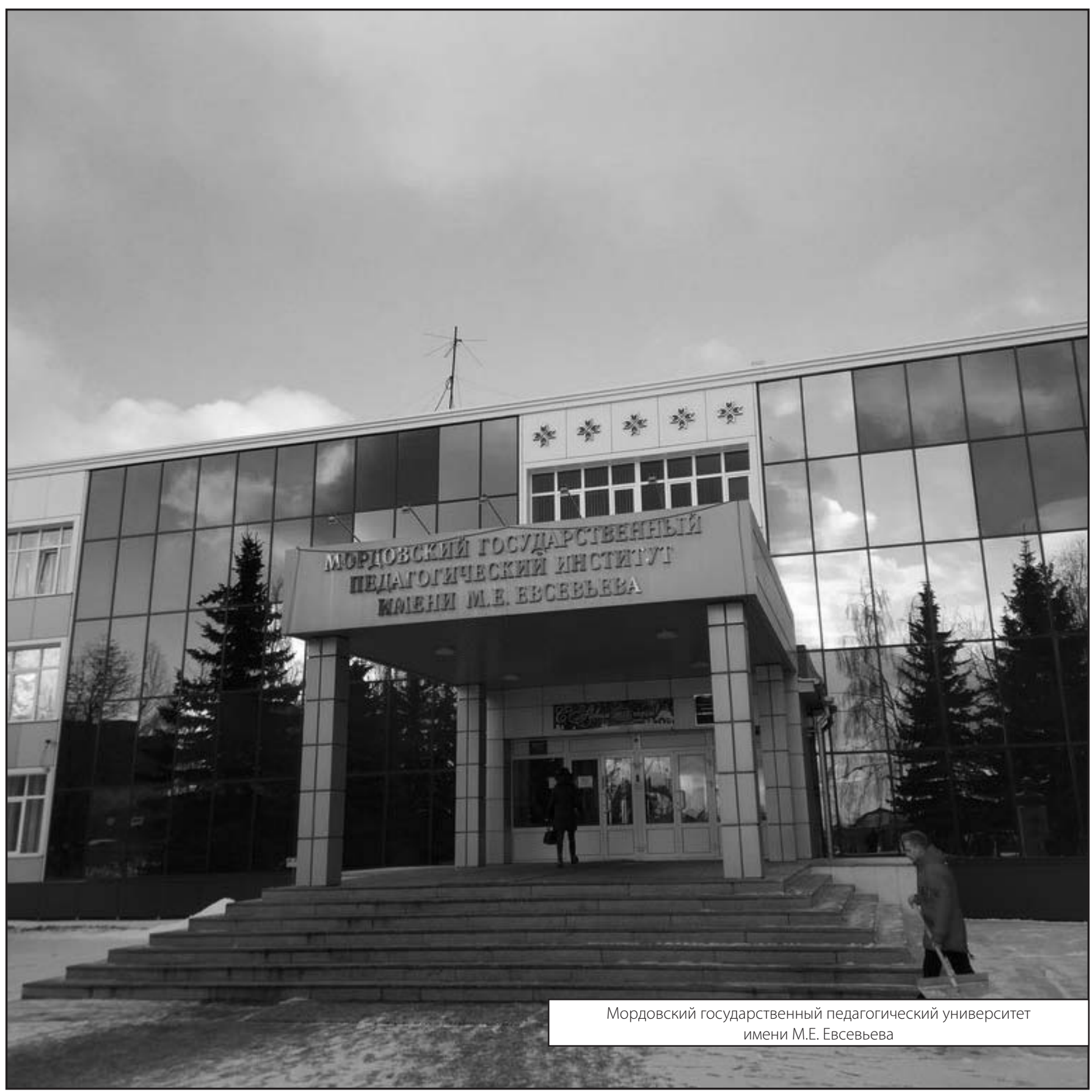

